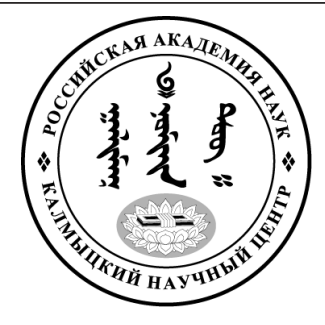

Published in the Russian Federation

Oriental Studies (Previous Name: Bulletin of the Kalmyk Institute for

Humanities of the Russian Academy of Sciences)

Has been issued as a journal since 2008

ISSN: 2619-0990; E-ISSN: 2619-1008

Is. 3, pp. 378-389, 2019

DOI: $10.22162 / 2619-0990-2019-43-3-378-389$

Journal homepage: https://kigiran.elpub.ru

УДК $392.8(=512.31)+94(571.53)$

\title{
Влияние земледелия на систему питания в Предбайкалье во II половине XIX - I половине XX вв. (на примере аларских бурят)
}

\author{
Галина Виссарионовна Махачкеева ${ }^{1}$ \\ ${ }^{1}$ Восточно-Сибирский государственный институт культуры (д. 1, ул. Терешковой, 670031 Улан- \\ Удэ, Российская Федерация) \\ аспирант \\ ORCID: 0000-0002-7558-9302. E-mail: ecoprint@inbox.ru
}

\begin{abstract}
Аннотация. Введение. Основываясь на исследованиях отечественных этнографов и собственных полевых материалах автор впервые рассматривает локально-региональный характер питания, связанный с земледельческими традициями, бытовавшими в XIX-XX вв. на территории, населенной бурятами, в прошлом называемыми балаганскими. Сегодня это в основном земли современного Аларского района Усть-Ордынского Бурятского округа Иркутской области, издревле отличавшиеся своим плодородием. Сохраняется эта позиция и в наши дни: на долю района приходится 20 \% зерновых в целом по области и 40 \% - по округу. Данное обстоятельство, по мнению автора, объясняет тот факт, что земледелие явилось определяющим фактором возникновения своеобразной локальной кухни, построенной на сочетании мясных, молочных и мучных продуктов. Это значительно отличало модель питания аларских бурят от пищи монгольских народов, в которой преобладала мясо-молочная направленность. История вопроса. Аларские буряты как этнотерриториальная группа подробно не исследованы, и система их питания не стала объектом изучения, хотя она свидетельствует о наличии самобытной культуры, имевшей древние корни. Задача: исследование растительной основы традиционной кухни одной из локальных групп бурят западного побережья Байкала. Результаты. Автор приходит к выводу, что автохтонными компонентами в национальной кухне аларских бурят являются элементы не только собственно кочевой монгольской культуры, но и земледельческой, тюркской, которая, как известно, издревле представлена на территории Южной Сибири. Это обстоятельство подтверждается неизвестными ранее данными, которыми являются сходство многих блюд, их названий, технологии обработки продуктов и приготовления. Также автор выявляет влияние русской культуры, в результате чего были освоены новые технологии и растительные продукты, заметно обогатившие национальную кухню.
\end{abstract}

Ключевые слова: предбайкальские или западные буряты, аларские буряты, тюрки, земледелие, система питания, зерновые, хлеб, мука

Для цитирования: Махачкеева Г. В. Влияние земледелия на систему питания в Предбайкалье во II половине XIX - I половине XX вв. на примере аларских бурят. Oriental Studies. 2019;(3):378-389. DOI: 10.22162/2619- 0990-2019-43-3-378-389. 
UDC $392.8(=512.31)+94(571.53)$

\title{
The Impact of Agriculture on Western Baikalia's Food System in the Mid-to-Late $19^{\text {th }}$ and Early-to-Mid $20^{\text {th }}$ Centuries: a Case Study of the Alar Buryats
}

\author{
Galina V. Makhachkeeval \\ ${ }^{1}$ East-Siberian State Institute of Culture (1, Tereshkova Str., Ulan-Ude 670031, Russian Federation) \\ Postgraduate Student \\ ORCID: 0000-0002-7558-9302.E-mail: ecoprint@inbox.ru
}

\begin{abstract}
Introduction. The traditional food system of Biakalia's residents still remains understudied. The available works primarily focus on dairy and meat products, and almost ignore the plant food system, which is due to the fact the agricultural traditions of Baikalia's native populations that had attained quite a high level of agronomy in ancient times - have not been explored. The traditions basically concentrated in a relatively small area occupied by present-day Alarsky District of UstOrda Buryat Okrug (Irkutsk Oblast) and former Balagansky Uyezd of Irkutsk Governorate. Historical Background. Since ancient times the Alar Valley served as the main breadbasket of the region. Being the leading grain producer in the whole region, it retains this position even nowadays. During the period in question, in the $19^{\text {th }}$ and $20^{\text {th }}$ centuries, agriculture was already the key sector of economy. This had been determined by the early sedentarization of the Alar Buryats resulting from beneficial geographical conditions, as well as somewhat genetic skills. So, the factor determined the food system of Buryats in that area. Goals. Taking into account the available ethnographic research and comparative data on the material culture of Turkic peoples, as well as own field data, the article seeks to explore the unique Alar Buryat cuisine and examines the grain-based nutritional system which includes most common cereals. It also describes the crops cultivation and cooking technologies, and analyzes the terminology. Results. The study reveals a previously unknown number of autochthonous specific features containing certain Turkic elements, such as similarity of many Buryat dishes, their names and cooking methods, tools and stoves characteristic to Turkic material culture. The article presents quite reasonable assumptions which prove somewhat close interaction between aboriginal peoples at an early stage of ethnic development, and also points out the large influence of Russian agronomic culture that brought new technologies and plant cultures, especially potatoes, thus significantly enriching nutritional ration. Some elements of spiritual culture also indicate the important role of cereals in life of the Alar Buryats. The study also concludes that the Alar Buryats had developed a food system where baked goods, meat and dairy constituted equal proportions. That was a major difference from food systems of other Mongolic peoples where meat and dairy prevailed. In general, this demonstrates that the ethnic group has high adaptive capacity, an ability to manage and efficiently interact with the changing external environment. The previously unknown terms and elements of Alar Buryat material culture are valuable enough for science.
\end{abstract}

Keywords: Buryats of Western Baikalia, western Buryats, Alar Buryats, agriculture, food system, grain, bread, flour, Turks

For citation: Makhachkeeva G. The Impact of Agriculture on Western Baikalia's Food System in the Mid-to-Late $19^{\text {th }}$ and Early-to-Mid $20^{\text {th }}$ Centuries: a Case Study of the Alar Buryats. Oriental Studies. 2019;(3):378-389. DOI: 10.22162/2619- 0990-2019-43-3-378-389.

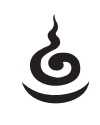

\section{Введение}

Образ жизни этноса определяет не только среда, но и способность усваивать дары этой природной среды, «возвращать их как результаты своего труда, обеспечивая не только свои потребности, но и потребности всего этноса, вкладывая в удовлетворение этих потребностей „свою долю“. Иными словами, характер производства и потребления материальных и духовных благ - 
важнейший показатель уровня социокультурного развития любого этносоциального объединения, любого этноса» [Бромлей 2008: 430].

Хозяйственная деятельность, обусловленная географической средой и уровнем социально-экономического развития, в значительной степени определила и особенности материальной культуры монголо-язычных народов, включая и такой его компонент, как пища. Как известно, основным видом их деятельности являлось кочевое скотоводство, и именно древние скотоводческие традиции выработали систему питания, основанную на молочных и мясных продуктах. Это направление, в том числе локальный характер питания разных групп бурят, в этнографической литературе описывали, в частности, М. Н. Хангалов, Г. Р. Галданова [Хангалов 2004; Галданова 1992]. Использование продуктов скотоводства в питании бурят разных регионов было рассмотрено И. Б. Батуевой [Батуева 2013].

\section{Постановка задачи}

Основываясь на трудах ученых, полевых и сопоставительных материалах, исследовать растительную основу системы питания аларских бурят, относящихся к группе предбайкальских, населяющих земли в левобережье Ангары, южной части современной Иркутской области.

\section{Основная часть}

Под влиянием географических условий и исторических процессов у некоторых бурятских этнических групп сложились иные способы использования естественных средств жизни, вследствие чего традиции претерпевали множество изменений. Например, у бурят, населяющих западный берег Байкала, и поэтому называемых западными или предбайкальскими, в XIX в. окончательно складывается оседлый образ жизни.

В правобережье Ангары преобладало скотоводческо-земледельческое, в левобережье - земледельческо-скотоводческое хозяйство, что определило образ жизни бурят Предбайкалья, в том числе и характер их питания. Эту мясо-молочно-зерновую систему питания на основе архивных и литературных источников рассмотрел А. А. Бадмаев [Бадмаев 2011].
Отдельно же растительная основа пищи не рассматривалась - так же, как и не изучены именно земледельческие традиции бурят. На наш взгляд, это произошло по той причине, что бытовали эти традиции на сравнительно небольшой территории, там, где было наиболее развито земледелие, - в южной части Приангарья, на землях, населенных бывшими балаганскими бурятами. После затопления части территории водами Братского водохранилища сейчас это в основном земли в пределах современных Аларского и Нукутского районов Иркутской области.

Известно, что этот предбайкальский регион в средневековье населяли племена, сеявшие пшеницу, просо, ячмень, гречиху, коноплю. По мнению Д. М. Маншеева, «земледелие в Прибайкалье было порождением соответствующей политики Тюркского каганата в период его расцвета» [Маншеев 2011: 17], затем оно было поддержано курыканами, которых относят преимущественно к тюркам.

О присутствии тюрков в составе аларских бурят свидетельствуют архивные документы [Зимин 2004: 126]: роды уhар, уйгар, баахай - от уйгуров, род сартул (hартул) - от тюрко-бухарских племен.

Осколками саянских тюрков считаются долонгуты (долоонгууд), о которых устных сведений нет, зато есть упоминания в исторической литературе. В XVII в. они назывались теленгитами (в русских источниках - долонгутами), и под именем $\partial a$ лянь упоминались в китайских летописях конца V в., которые зачисляли их в группу гао-гюйских родов, в жилах которых текла динлинская кровь [Дугаров 1983: 92].

Также в Аларскую степь шла постоянная миграция саянских тюрков, сойотов и урянхайцев. За невест указанных народов калым платили мукой или зерном. Это было выгодно, так как при этом обходились без свадебных обрядов. Так, Ж. А. Зимин приводит пример женитьбы своего деда Махляна (Михаила), который родителям невесты из окинского рода уляба заплатил один мешок муки и три мешка ржи [Зимин 2004: 135].

Подобные примеры может привести и автор этих строк, в роду которого в конце XIX - начале XX вв. было заключено два таких брака. Кроме того, по археологическим 
данным, в этом регионе были согдийские колонии (Унгинское поселение, датируемое XII-XIV вв.), которые занимались земледелием [Дашибалов 1997: 44; Курышов 2014 : 571].

На берегу оз. Аляты был обнаружен, наряду с остатками неолитической стоянки, земледельческий инвентарь, датируемый VI-XI вв. Расстояние между этими двумя археологическими ареалами не превышает 50-70 км [Зимин 1983: 104, 108].

Возможно, что древние земледельческие навыки были унаследованы поздними культурами, в том числе и бурятской. Неслучайно аларцы, вместе с идинцами и балаганцами, занимали первое место в земледелии среди всего бурятского населения [Зимин 2004: 63]. А по размерам посевных площадей на душу населения в начале XIX в. аларские буряты были лидерами [Маншеев 2011: 20].

Более 90 \% пашни до революции отводилось под зерновые. Пшеница была одной из ведущих культур, хотя известно, что это самый трудоемкий вид для возделывания. В процессе такого длительного стабильного проживания в условиях устоявшейся системы хозяйствования аларские буряты выработали свой характер питания, отличающийся от других монголо-язычных народов тем, что значительную долю в нем, наряду с молочными и мясными, занимали мучные продукты.

В прошлом 'зерно' таряан размалывалось и на домашних жерновах, и на водяных мельницах, имеющих одно название тээрмэ (родственные тюркские эквиваленты: тирмэн у сибирских татар, тэрбен - у чулымских тюрков, тербен - у шорцев и кумандинцев) [Тюркские народы 2006: 50, $153,263,363]$. Продолжим эту аналогию хакасским теербен [Бутанаев 1993: 162]. Тюркского же происхождения, думается, и слово талхан, употребляемое западными бурятами в значении 'мука', а восточными — в значении 'хлеб'.

«Толканом называется растолченный ячмень, поджаренная мука из него, толокно у всех тюрков Алтая, Саян и сопредельных территорий, как и у средневековых тюрков. Миллер приводит два названия муки толкан и ун. Оба названия в письменных источниках известны, по крайней мере, с XI в.» [Тюркские народы 2006: 153].
Мука пшеничная у аларцев называлась сагаан талхан 'белая мука', хара талхан (досл. черная мука) 'ржаная мука', мука из поджаренных в котле зерен - аaгаһaн, из толченого зерна — ороот таряан. Традиционным видом хлеба у аларцев были толстые лепешки из пресного теста хабтани, хабтанди. Их готовили из любой муки на воде и жарили в малхаане 1 'котле'.

Готовят хабтани на сковороде и в наши дни, при отсутствии в доме общеизвестных видов хлеба. Лепешки не резали, а 'отламывали' зуһэмэлхэ.

Также лепешки на молоке пекли на специальных каменных плитах, уложенных на горячую золу очага. Из толченого, жареного зерна, смешанного со сметаной или маслом, пекли боон 'хлебцы' типа печенья. Позже стали использовать чугунный настил варочных плит (иэрэм дээрэ), на которых пекли лепешки из тонкого теста - хатаама. Созвучное название - каттама имели пресные лепешки и у многих татар [Тюркские народы 2006: 85]. Хлеб же из кислого теста пекли в уличных хлебопечах. Наличие таких печей на деревянном помосте «в одноулусной загороди, в одном круге единокровно-родственных юрт» отмечал в 1875 г. А. П. Щапов [Щапов 1875: 199]. Позже о них писали К. Д. Басаева, Ж. А. Зимин [Басаева 1993; Зимин 2004].

Заметим, что такие печи характерны для тюрков. Так, например, у сибирских татар для выпечки хлеба применялись узкие печи летнего типа, устанавливаемые на специальных помостах во дворах [Тюркские народы 2006: 65].

Хлеб пекли в этих печах прямо на поду, независимо от сезона - и зимой, и летом. Зимой пекли, не прикасаясь к тесту руками:

1 Котел-малхаан встраивался сбоку к небольшой варочной печи (ранее она называлась мангад соол 'русская печь', термин же соол относится к тюркизмам [Рассадин 1986: 10].) Мал-

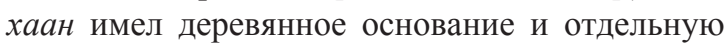
топку. Такие вмазанные в печь котлы тоже характерны для тюркских народностей. Это своего рода универсальное сооружение, сочетающее кочевнический котел и печь, позволяло варить мясо, супы, чай, жарить лепешки и блины. Думается, что есть необходимость отдельно рассмотреть указанные печные сооружения, так как в данном случае любопытно само сохранение элементов этнических традиций. 
широкой деревянной лопаткой наполняли тестом большую выдолбленную из дерева миску, предварительно обсыпанную мукой. Затем несколько раз встряхивали её и опрокидывали тесто на деревянную лопату, которую быстро отправляли в печь. В итоге получали необыкновенно вкусные, с хрустящей корочкой хубэрэг 'караваи'. По этой причине в Аларской долине всегда отдавали предпочтение подовому хлебу, поэтому уличные хлебопечи можно увидеть и сегодня. Кусочки такого хлеба в сливках - блюдо хоймог - особенно любили дети. Хлеб пекли часто, особенно в больших семьях. Например, в семье с девятью детьми каждый день [ПМА: с. Киркей Аларского района Иркутской области].

Сегодня сложно установить источник возникновения теста. Как видим, национальная кухня аларцев формировалась в тесном взаимодействии с тюркскими народами, в частности с татарами, которые знали кислое и пресное тесто, причем кислое готовилось, как и у русских [Воробьёв 1930: 145]. Ставилось эдьхуургэ 'тесто' в торхо 'квашне' в виде кадушки. Такие кадушки для хранения продуктов были разных видов: для аарсы - аарсайн торхо, зерна таряани торхо, муки - талхани торхо.

Поскольку мучные продукты готовили ежедневно, то имелась специальная кадушка для просеянной муки - сээлэнсэ - круглая, выдолбленная из основания толстого дерева, чтобы не прогрызли мыши. В эту емкость мука просеивалась через 'сито' hяагуyр, шэлхуур, высевки назывались урьеэдэһэн (все эти термины не зафиксированы в словарях).

Готовая мука приносилась из амбара в берестяных бортого 'вёдрах'. Тесто мешали худхуур(га) 'мутовкой'. Маленькие булки ставили на ундээлгэхэ 'расстойку' в деревянных тахиш 'корытцах' (эти слова также не зафиксированы). В них же в вертикальном положении оставляли горячий хлеб, вынув из печи. Известна была бурятам и эхэ 'опара', и эдьхуургэ 'закваска'. Термин же хилеэмэ 'хлеб' был позже заимствован в результате контактов с русскими переселенцами также, как и способы выпечки разных мучных изделий [ПМА: с. Кукунур Аларского района Иркутской области].

В домашних небольших печах на сан 'противнях' пекли хотируухай 'калачи' и шаанья 'булочки' - вид сибирских шанег, поверхность которых промазывали сметаной или маслом. Готовили открытые (в основном) и закрытые круглые пирожки из пресного и кислого теста с разными начинками, чаще с мясом, потрохами, картофелем, яйцами, жарили их на сковороде или в котле-малхаане. Пекли пироги и сдобные булочки 'таарка' (термин не зафиксирован) со сладкими начинками из ягод, смешанных со сметаной (самой популярной была главная ягода в Аларской долине зэдэгэнэ 'земляника', которую сушили на зиму) [ПМА: п. Кутулик Аларского района Иркутской области].

Особым лакомством была такая земляника, сваренная в hоорлоһон 'кипяченой' (термин в словарях отсутствует) сметане с небольшим количеством воды. Позже, с появлением сахара, стали варить варенье. Также пекли разного рода печенье, к праздничному столу обязательно жарили хворост, который можно было долго хранить, особенно зимой. Поэтому хворост входил в состав неприкосновенного запаса: у каждой аларской хозяйки в укромном месте имелся продовольственный набор, в который входили винно-водочные изделия, хороший чай, сладости, продукты долгого хранения. Все это хранилось на случай внезапного прихода гостей, которых принято было принимать всем родом. Даже дети знали, что эти продукты трогать нельзя: айшуудта улээгты!! 'оставьте гостям!'.

Пекли лепешки на основе разных молочных продуктов: простокваше, кефире, сыворотке, пахте. На уураг 'молозиве' получались питательные, ярко-желтого цвета большие пышные оладьи. Всегда были популярны алаада 'блины', которые пекли в чугунных формах с бортиками или в специально для этого приспособленных старых котлах. Такие алаадын тогоон 'котлы', с отбитыми верхними краями (видимо, для легкости), хозяйки ценят и сегодня, так как появившиеся современные котлы для блинов не выдерживают конкуренции, поскольку стенки у них пологие и блины получаются бесформенными.

Под котлом разжигали огонь и лили на раскаленные стенки жидкое тесто, которое стекало вниз, приобретая треугольную форму. Получившиеся блины обмакивали в сметану, складывали стопочкой и оставляли 
пропитаться. Следует добавить, что термин алаада имеет общий корень с тюркским алай, в частности, так называются блины у телеутов [Тюркские народы 2006: 201]. И по технологии изготовления это блюдо тюркское. Вероятно, слово ошибочно считают производным от русского «оладьи» [Махачкеева 2018: 374-382].

Без муки невозможно представить главное кушанье аларцев - манаһан зоохэ 'саламат', который обязательно готовили для гостей. В кипящую сметану, помешивая, подсыпали немного пшеничной или ржаной муки и мешали до выделения масла, затем добавляли воды и муки и вновь помешивали. Готовность определяли по выделившемуся на поверхности маслу.

Саламат - это главное блюдо для любых торжеств, обязательным являлся он и для обрядов. Поскольку блюдо считалось сакральным, сразу же после варки первинкой саламата угощали огонь. Известно, что если хозяйка забывает угостить хозяина очага, то впоследствии саламат ей не удается, то есть масло не выделяется, и в результате получается густая невкусная каша.

Отметим, что саламат издревле был известен у тюркских народов, был заимствован русской и украинской (саломаха) кухнями и упоминался в различных указах начиная с XVI в. [Махачкеева 2018: 379].

Буряты, по мнению исследователя Н. Б. Дашиевой [Дашиева 2012: 30] название «саламат» не знали. В Алари же саламат всегда считался самым главным и почетным блюдом и упоминался еще в преданиях XVII в. [Зимин 1983: 105]. Так, легенда гласит, что после пира перед зэгээтэ аба (облавная охота в XVII в. еще существовала) «один из облавщиков стал царапать ( haбардаха) ногтями котел, чтобы собрать и доесть остатки саламата ${ }^{2}$, остальные участники предстоящей охоты прозвали этого человека hабар, от него впоследствии произошел род хабарнут (һабарнууд)», относящийся к аларским хонгодорам. Возможно, в бурятской кухне саламат начал свое распространение с Алари. В пользу этого предположения говорят и такие факты: во-первых, саламат требует обилия сметаны, что обеспечивает только КРС, для разведения кото-

${ }^{2}$ Сюрмаһан 'корочкой', образовавшейся на дне посуды, в которой варился саламат, особенно любят полакомиться дети. рого нужен хороший травостой, характерный для Аларской долины. Правобережье же Ангары, заселенное основной частью западных бурят, не отличается высоким травостоем. Ранее из-за этого, например, в Баяндаевском районе практиковалось от двух до трех кочевок, тогда как в Алари одна [ПМА: Баяндаевский район Иркутской области].

В летние месяцы, когда молочные продукты появлялись в изобилии, саламат становился частым кушаньем. В связи с этим в старину возник один из основных летних праздников - Зоохэ наадан 'Саламатная вечерина', когда со всех дворов собирали сметану и в больших котлах варили саламат, главное блюдо вечера, которым потчевали всех присутствующих, а в первую очередь - гостей, приехавших из окрестных деревень мунгалдаха 'посостязаться' в песенных турнирах и ёхорных плясках [ПМА: Аларский район Иркутской области]. Во-вторых, мука - второй необходимый ингредиент саламата, в зерноводческом хозяйстве продукт постоянный. Следовательно, если учесть вышеизложенный факт о том, что автохтонное ядро населения в Аларской долине было тюркоязычным, то версия о распространении саламата из Алари выглядит обоснованной [Махачкеева 2018: 380].

Вторым популярным кушаньем у аларцев являлся иулээн - мясной суп с домашней лапшой, которую готовили часто, в некоторых семьях - каждый вечер, когда все были в сборе: муку смешивали с подсоленной водой (позже стали добавлять яйцо) и делали крутое, эластичное тесто, которое затем раскатывали, немного подсушивали, скручивали в рулет и резали на тонкие длинные полоски ${ }^{3}$. Принято было как можно тоньше нарезать лапшу и по тому, как она нарезана и не слипается ли при этом, оценивали хозяйку. Аларские женщины славились умением делать эластичное тесто для лапши так, что когда его вывешивали на веревке для быстрой просушки, оно не рвалось и при варке не слипалось. С такой лапшой варили и молочные супы, в которые

\footnotetext{
${ }^{3}$ У закаменских бурят, по данным Г. Р. Галдановой [Галданова 1992: 83], для лапши покупали высококачественную белую муку, которая называлась крупчаткой. Лапшу разрезали на «довольно широкие полоски».
} 
добавлялись взбитые яйца. Отдельным блюдом была лапша, сваренная густо, как каша, на молоке, смешанная со взбитыми яйцами и луком. Катали лапшу и впрок, предварительно хорошо просушив. И в наши дни, несмотря на большой ассортимент макаронных изделий, суп с домашней лапшой остается популярным блюдом на столе аларских бурят. Вероятно, это блюдо тоже тюркского происхождения, так как к группе татарских «национальных кушаний относятся супы шурпа-шулпа, которые представляют собой собственно бульон из-под вареного мяса, приправленный мукой. Такие жидкие блюда имеются у многих кочевых турок и употребляются в той или иной комбинации с вареным мясом. Татары только усовершенствовали это блюдо, введя большее оформление в прибавляемые кусочки теста» [Воробьёв 1930:144]. Термин же «лапша», согласно Этимологическому словарю русского языка М. Фасмера, заимствован из тюркского лексического фонда [Фасмер].

Зимой лепили и замораживали в большом количестве пельмени, которые подавались обязательно с шулэтээ 'бульоном'. Варили с мукой и аapcy - густой молочный напиток, который пили и в горячем, и в холодном виде. Он был уникален тем, что обладал согревающими свойствами зимой и охлаждающими, с добавлением молока и сметаны, - летом, поэтому незаменим был в любую страду. С аарсой варили каши тибэһэн и амһан из жареного, толченого зерна ярицы, пшеницы на воде или молоке, заправляя сметаной. Каши эти различались тем, что зерна проходили разные стадии обработки. Также варили полужидкие каши на мясном бульоне. Каленое зерно было лакомством для детей, брали его с собой и в дорогу.

В советское время aаpcy, перешедшую в разряд редких продуктов из-за антиалкогольной политики, в кашах стали заменять творогом, заливая сметаной. Готовили пареную рожь или пшеницу с мясом, с потрохами, таряатай шулээн 'супы с зерном' и разными крупами, оставляя на несколько часов в горячих печах или котлах-малхаанах. С мукой аларцы варили сытный питательный чай - тогоон сай или затураан. Для этого в вытопленный в котле мелко искрошенный жир добавляли муку и помешивая поджаривали до золотистого цвета, затем вливали заваренный черный чай и кипятили. Пили этот густой чай чуть подсоленным. Любопытным представляется тот факт, что затураан имеется и в татарской кухне - «поджаренная на масле или жире мука, отваренная затем в чае» [Тюркские народы 2006: 85]. Известен саторан и у хакасов, только более густой консистенции. У русских в Сибири все виды указанной каши называются саламатом. [Тюркские народы 2006: 576]. Термин же сай у татар тоже означает чай [Воробьёв 1930: 155].

Следует отметить особое отношение аларских бурят к хлебу в связи с тем, что в их сознании он четко ассоциировался с плодородием, прибылью, защитой. Об этом свидетельствуют, например, такие факты: при обряде зарывания последа в горшке с последом обязательно должны были быть зерно или хлеб, чтобы ребенок расплодился как зерно. Охранную же силу хлеба использовали, к примеру, в таких случаях: водку принято было прятать в ларях с мукой, зерном, а если бутылка початая, хотя бы просто положить рядом кусок хлеба. Считалось, что в таком случае вокруг нее не будет собираться нечисть. У бурят других этнических групп на бутылку кладут сагаан мунгэн 'белые монеты'.

Другой пример: у аларских бурят принято было на свеженину созывать всех родственников и соседей. Во время массового забоя скота в семьях даже не варили горячую еду ввиду отсутствия в этом необходимости, так как в такие дни столовались у родных. Тем же, кто не смог прийти по какой-либо причине, отправляли немного парного мяса (шарууга эльгэхэ или зэмһэн 'подарок', 'подношение' при закалывании животного), непременно положив на него кусок хлеба в знак чистоты и защиты, особенно это нужно было соблюдать в темное время суток.

Кроме того, у аларцев существовало поверье, что если душа человека, преследуемая злыми духами, спрячется в хлебе, то духи не смогут найти и поймать ее. Как видим, земледелие нашло свое отражение и в духовной культуре аларских бурят, что тоже требует отдельного исследования. Также интерес представляют аларские талхаар балталха 'методы лечения мукой': припарки, вытяжные компрессы, обертывания. 
Выращивали аларские буряты и овощные культуры: «у инородцев (балаганских бурят. - M. Г.) в огородах каждогодно сажается картофель, капуста, репа, ретька, морковь и частию огурцы, свекла и лук, на продажу сеи овощи не поступают, употребляют оные на собственное продовольствие» [Бадмаев 2011: 41].

Сажали также горох и бобы, особенно культивировали аларцы брюкву [Бадмаев 2011]. Самым востребованным был 'картофель' яабул, яабал $(x a)^{4}$, который варили и жарили на масле, сале, добавляли во все супы, молочный в том числе. Готовили в котле или печи с мясом, потрохами с небольшим количеством воды. Была популярна 'картофельная каша' шобхой: в пюре, разбавленное картофельным отваром, постепенно размешивая добавляли муку и варили на медленном огне, при необходимости наливая горячее молоко. Ели такую кашу с маслом или сметаной.

В советское время, особенно во время войны, на аларских полевых станах эта каша была одним из основных блюд, поэтому её называли «колхозной». Сытным блюдом был толченый картофель, смешанный со шкварками или сметаной, диким луком (мандиһан) или диким чесноком (гоогоһон), которые заготавливали в большом количестве. Особенно хорош был в таком виде молодой картофель.

Следует отметить один примечательный факт: с осени до весны в любой семье каждый день можно было увидеть на плите картофель в мундире, который после варки раскладывали поджариться. Если к вечеру картофель не съедали, его отправляли на корм скоту, а наутро ставили варить новую порцию. Этот факт можно объяснить тем, что в долине всегда были неизменно хорошие, независимо от погодных условий, урожаи картофеля. К примеру, семья из 5 человек, высаживая весной 5 мешков картофеля, осенью собирала урожай в количестве от 50 до 70 мешков. Картофелем доверху забивалось подполье, излишки же продавались и скармливались скоту [ПМА: Аларский район Иркутской области]. Также этим обстоятельством можно объяснить наличие в лексике аларцев редкого слова эдгэрхэ,

4 Отметим, что так же называется яаблах ‘картофель' у хакасов [Хакасско-русский 2006: 1061]. в переводе на русский язык означающего следующее: картофель становится жестким (дубеет - просторечное) при неправильной варке и поэтому непригодным для еды. В литературном бурятском языке и в других говорах это слово отсутствует.

Другие овощи варили, запекали, ели в свежем виде, добавляли в супы. Заготавливали на зиму капусту в больших бочках, огурцы - в кадушках, также в кадушках солились һарсяаг 'грузди', а способы заготовки были заимствованы у русских переселенцев.

Как видим, мучные продукты, наряду с мясными и молочными, занимали в рационе аларских бурят, как и в целом у предбайкальских, значительное место. Об этом свидетельствуют и официальные данные: «Западные бурят-монголы в значительной части земледельцы, восточные же скотоводы. Потребление у них различно: западные бурят-монголы потребляют больше хлеба и меньше мяса, восточные больше мяса, при соответственно меньшем потреблении хлеба. По данным анкетного обследования 1917 г., западными бурят-монголами потреблялось в год 14,3 п. хлеба в зерне и 3-4 пуда мяса».

По данным Агинской экспедиции 1908 г., агинскими бурят-монголами потреблялось 6,9 пуда мяса в год.

Таблица 1. Потребление хлеба и мяса на 1 душу в год

[Table 1. Annual per capita consumption of bread and meat]

\begin{tabular}{|l|c|c|}
\hline $\begin{array}{l}\text { Группы населения } \\
\text { [Population groups] }\end{array}$ & $\begin{array}{l}\text { Хлеб в зерне } \\
\text { [Grain bread] }\end{array}$ & $\begin{array}{l}\text { Mясо } \\
\text { [Meat] }\end{array}$ \\
\hline Зап. бурят-монголы & 15,4 & 2,6 \\
\hline $\begin{array}{l}\text { Вост. бурят-монголы, } \\
\text { в том числе агинск. } \\
\text { бурят-монголы }\end{array}$ & 3,7 & 4,6 \\
\hline Средняя (взвешенная) & 7,6 & 6,12 \\
\hline
\end{tabular}

Примечание. В таблице использованы данные бюджетного обследования 1923 г. [Клобуков 1925: 80].

Исследователь И. И. Серебренников [Серебренников 1925: 163] в своей книге «Буряты, их хозяйственный быт и землепользование» в 1925 г. приводит аналогичные данные о потреблении в 1917 г. бурятами Балаганского уезда зернового хлеба и 
картофеля в сравнении с русскими крестьянами.

Таблица 2. Потребление зернового хлеба и картофеля на 1 душу обоего пола в год (в пудах)

[Table 2. Annual per capita (regardless of gender) consumption of grain crops and potatoes (measured in Russian poods)]

\begin{tabular}{|l|c|c|}
\hline $\begin{array}{l}\text { Группы населения } \\
\text { [Population groups] }\end{array}$ & $\begin{array}{c}\text { Зерновой } \\
\text { хлеб } \\
\text { [Grain crops] }\end{array}$ & $\begin{array}{c}\text { Картофель } \\
\text { [Potatoes] }\end{array}$ \\
\hline $\begin{array}{l}\text { Русские крестьяне- } \\
\text { старожилы }\end{array}$ & 22,9 & 6,5 \\
\hline $\begin{array}{l}\text { Русские крестьяне- } \\
\text { переселенцы }\end{array}$ & 12,9 & 10,0 \\
\hline Буряты & 21,4 & 5,1 \\
\hline
\end{tabular}

При этом, по мнению К. Д. Басаевой и Ж. А. Зимина [Басаева, Зимин 1988: 73], «мясная и молочная пища у бурят по-прежнему занимала значительно больший удельный вес в пищевом рационе, чем у русских крестьян».

Выявленные факты позволяют сделать вывод о том, что в процентном соотношении мясные, молочные и мучные продукты в рационе аларских бурят составляли равные доли, что является характерным отличием от пищи монгольских народов, об общих чертах в питании которых писали исследователи. Так, Георги отмечал не только сходство, а полное тождество в питании калмыков, бурят и монголов, описывая их на одном временном отрезке. Сообщая о преобладании мясной и молочной пищи, он писал, что мучные продукты употреблялись редко, а общеупотребляемым напитком являлся кирпичный чай [Пахутов 1983: 33]. У аларцев же кирпичный зеленый чай не получил распространения. Скорее всего, по той причине, что, кроме особо почитаемых напитков - аарсы и чая затураан (описанные выше), которые варили круглый год, пили черный кирпичный чай, но непременно с 'молоком' һутэй или со 'сливками' сусэгээтэй, 'чай из чаги' маага сай. Отсутствие черного чая заменяли разные травы, в изобилии произраставшие благодаря черноземным почвам.

Популярными были отвары кровохлебки, пиона, шиповника, бадана, брусники, земляники, которые заготавливались на зиму. Но самым востребованным был чай из масаа сай 'кипрея' (иван-чая), который целыми плантациями рос в окрестных березовых лесах. В годы лихолетья такой чай у аларских бурят был основной заменой черного кирпичного [ПМА: г. Улан-Удэ].

Следует отметить, что иван-чай в XIX в. был необычайно популярен в России и за рубежом; изготовленный из его листьев чай был экспортным товаром и даже составлял конкуренцию индийскому. Целебные свойства кипрея достаточно изучены, он не содержит кофеин, что выгодно отличает его от других чаев. По мнению диетологов, для здоровья полезнее употреблять пищу своей местности. Ведь известно, что не всегда желудок справляется с продуктами другого региона, так как в организме может не оказаться ферментов, наличие которых зависит от изначального рациона наших предков. В этом контексте польза южного чая, содержащего кофеин, для нас, жителей северных широт, кажется сомнительной. Хочется надеяться, что кипрей удостоится когда-то внимания исследователей, и былая слава русского чая будет возрождена.

\section{Заключение}

Приведенные материалы свидетельствуют о том, что зерновая направленность хозяйства, обусловленная природными и социально-экономическими условиями, полностью определила своеобразную локальную модель питания аларских бурят со сбалансированным сочетанием мучных, мясных и молочных продуктов. Это в значительной степени отличалось от мясо-молочной направленности традиционной пищи монгольских народов. Кроме того, отличительным признаком являлось сходство многих блюд, способов обработки продуктов, технологии приготовления, а также терминов, с традиционными элементами тюркской кухни, что свидетельствует об их древнем происхождении. Эти ранее неисследованные факты еще раз подтвердили общеизвестное тесное взаимодействие бурят Предбайкалья на раннем этапе развития с племенами сибирских тюрков.

Выявлены также новые данные более позднего большого влияния русской культуры, принесшей много новых технологий и растительных продуктов, относительно быстро вписавшихся в традиционную кухню аларских бурят. 
Таким образом, можно сделать вывод о формах высокой адаптации аларцев к среде обитания: умении приспосабливаться к нововведениям, обогащая свою жизнь и сохраняя при этом этническое своеобразие; рационально пользоваться богатствами, характерными для конкретной территории, взаимодействовать с внеэтнической социальной средой.

К сказанному следует добавить, что представляет интерес и кулинарная терминология, связанная с растительной основой питания, до сих пор нигде не зафиксированная и поэтому неизвестная современным бурятским лингвистам. Интересны должны быть для этнографов и отдельные элементы материальной культуры, например, печи, бытующие только в данной местности, связанные со своеобразной кухней, позволяющие выявить их этническое происхождение и связь культурных взаимовлияний.

\section{Полевые материалы автора}

1. ПМА: с. Киркей Аларского района Иркутской области: Харханова А. М., 2016.

2. ПМА: с. Кукунур Аларского района Иркутской области: Хинхаева Е. И., 2016.

3. ПМА: п. Кутулик Аларского района Иркутской области: Бабаринова В. А., 2018.

4. ПМА: Баяндаевский район Иркутской области: Болхосоев С. Б., 2017.

5. ПМА: с. Аларь Аларского района Иркутской области: Дамбинов Р. Д., 2016.

6. ПМА: с. Кукунур Аларского района Иркутской области: Ухакшинова А. М., 2017.

7. ПМА: г. Улан-Удэ, Республика Бурятия: Балыкова И. С., 2017.

\section{Author's Field Data (Informants)}

1. Babarinova V. A. Kutulik (village), Alarsky District, Irkutsk Oblast. Rec. in 2018.

2. Balykova I. S. Ulan-Ude, Republic of Buryatia. Rec. in 2017.

3. Bolkhosoev S. B. Bayandaevsky District, Irkutsk Oblast. Rec. in 2017.

4. Dambinov R. D. Alar, Alarsky District, Irkutsk Oblast. Rec. in 2016.

5. Kharkhanova A. M. Kirkey, Alarsky District, Irkutsk Oblast. Rec. in 2016.

6. Khinkhaeva E. I. Kukunur, Alarsky District, Irkutsk Oblast. Rec. in 2016.
7. Ukhakshinova A. M. Kukunur, Alarsky District, Irkutsk Oblast. Rec. in 2017.

\section{Литература}

Бадмаев 2011 - Бадмаев А. А. Система питания предбайкальских бурят первой половины XIX в. // Гуманитарные науки в Сибири. 2011. № 3. C. 35-38.

Басаева 1993 - Басаева К. Д. Поселения и жилища аларских бурят (вторая половина XIX - начало XX в.) // Из истории хозяйства и материальной культуры тюрко-монгольских народов: сб. науч. ст. Новосибирск: Наука, 1993. С. 52-89.

Басаева, Зимин 1988 - Басаева К. Д., Зимин Ж. А. Хозяйственный календарь аларских бурят (конец XIX - нач. XX вв.) // Культурно-бытовые традиции бурят и монголов: сб. науч. ст. Улан-Удэ: БФ СО АН СССР, 1988. C. $5-75$.

Батуева 2013 - Батуева И. Б. Буряты. Традиции скотоводческой культуры в XIX - начале XX века. Улан-Удэ: Изд.-полиграфическ. комплекс ФГБОУ ВПО ВСГАКИ, 2013. $143 \mathrm{c.}$

Бромлей 2008 - Бромлей Ю. В. Очерки теории этноса / послесл. Н. Я. Бромлей. 2-е изд., доп. М.: ЛКИ, 2008. 440 с.

Бутанаев 1993 - Бутанаев В. Я. Традиционная пища хакасов // Из истории хозяйства и материальной культуры тюрко-монгольских народов: сб. науч. ст. Новосибирск: Наука, 1993. С. $150-170$.

Воробьёв 1930 - Воробьев Н. И. Материальная культура казанских татар. Казань: Издание Дома Татарской культуры и Академического Центра ТНКП, 1930. 464 с.

Галданова 1992 - Галданова Г. Р. Закаменские буряты. Новосибирск: Наука, 1992. 170 с.

Дашибалов 1997 - Дашибалов Б. Б. Байкальская Сибирь в средние века. Улан-Удэ: Издво Бурятск. госун-та, 1997. 67 с.

Дашиева 2012 - Дашиева Н. Б. Традиционные общественные праздники бурят: история и типологии. Улан-Удэ: Изд.-полиграфическ. комплекс ФГБОУ ВО ВСГИК, 2012. 211 с.

Дугаров 1983 - Дугаров Б. С. О происхождении окинских бурят // Этнические и историко-культурные связи монгольских народов: сб. науч. ст. Улан-Удэ: БФ СО АН СССР, 1983. C. 90-101.

Зимин 2004 - Зимин Ж. А. Аларь: история и современность. Книга первая. Аларь - родная колыбель. Улан-Удэ: Издательско-полиграфическ. комплекс ВСГАКИ, 2004. 203 с.

Зимин 1983 - Зимин Ж. А. К вопросу о выходе хонгодоровских родов из Монголии и их 
расселении в Алари // Этнические и историко-культурные связи монгольских народов: сб. науч. ст. Улан-Удэ: БФ СО АН СССР, 1983. C. $102-113$.

Клобуков 1925 - Клобуков Б. Правительственно-кормовой баланс Бурреспублики на 1924-25 хозяйственный год // Газета «Жизнь Бурятии». 1925. № 1-6. С. 75-84.

Курышов 2014 - Курышов А. М. Культура земледелия у западных бурят // Историко-экономические исследования. 2014. Т. 15. № 3. C. 567-584.

Маншеев 2011 - Маншеев Д. М. Земледелие аларских бурят в XIX веке // Историко-экономические исследования. 2011. Т. 12. № 1. C. 17-29.

Махачкеева 2018 - Махачкеева Г. В. Тюркизмы в аларском говоре бурятского языка // Байкальские встречи - X: Культурная память и культурная идентичность в условиях глобализации. Мат-лы Междунар. науч. конф. Улан-Удэ: Изд.-полиграфическ. комплекс ФГБОУ ВО ВСГИК, 2018, С. 374-382.

Пахутов 1983 - Пахутов А. Е. Связь системы питания монголоязычных народов с их хозяйственно-культурным типом // Материальная и духовная культура калмыков: сб. науч. ст. Элиста: КНИИИФЭ, 1983. С. 27-36.

Серебренников 1925 - Серебренников И. И. Буряты, их хозяйственный быт и землепользование. Верхнеудинск: Бурят-монгольск. издво, 1925. 226 с.

Тюркские народы 2006 - Тюркские народы $\mathrm{Cu}$ бири / отв. ред. Функ Д. А., Томилов Н. А. М.: Наука, 2006. 677 с. (Серия «Народы и культуры»).

Фасмер - Фасмер $M$. Этимологический онлайн-словарь русского языка [электронный pecypc] // URL: https://lexicography.online/ etymology/vasmer/\%D0\%BB/ (дата обращения: 25.03.2019 г.).

Хакасско-русский 2006 - Хакасско-русский словарь / отв. ред. Субракова О. В. Новосибирск: Наука, 2006. 1114 с.

Хангалов $2004-$ Хангалов М. Н. Собрание сочинений. Т. 1. Улан-Удэ: Изд-во ОАО «Республиканская типография», 2004. 507 с.

Щапов 1875 - Щапов А. П. Бурятская улусная родовая община // Известия Вост.-Сиб. отдела РГО. Т. V. 1875. № 3-9. С. 198-223.

\section{References}

[Khakass-Russian dictionary]. Subrakova O. V. (ed.). Novosibirsk: Nauka, 2006. 1114 p. (In Russ.)

[Turkic Peoples of Siberia]. Funk D. A., Tomilov N. A. (eds.). Moscow: Nauka, 2006. 677 p. (In Russ.)
Badmaev A. A. The food system of Western Baikalia's Buryats in the early-to-mid $20^{\text {th }}$ century. Humanitarian Sciences in Siberia. 2011. No. 3. Pp. 35-38. (In Russ.)

Basaeva K. D. Settlements and dwellings of the Alar Buryats: mid-to-late $19^{\text {th }}-$ early $20^{\text {th }} \mathrm{cc}$. In: [The Turko-Mongols: Excerpts from the History of Economy and Material Culture]. Novosibirsk: Nauka, 1993. Pp. 52-89. (In Russ.)

Basaeva K. D., Zimin Zh. A. The economic calendar of the Alar Buryats: late $19^{\text {th }}-$ early $20^{\text {th }} \mathrm{cc}$. In: [The Buryats and Mongolians: Cultural and Household Traditions]. Ulan-Ude: Bur. Affil. Inst. of Sib. Branch of USSR Acad. of Sc., 1988. Pp. 57-75. (In Russ.)

Batueva I. B. [The Buryats: Traditions of a Livestock Breeding Culture in the $19^{\text {th }}$ and $20^{\text {th }}$ Centuries]. Ulan-Ude: East-Siberian State Inst. of Culture, 2013. 143 p. (In Russ.)

Bromley Yu. V. [Essays on the Theory of Ethnos]. $2^{\text {nd }}$ ed., suppl. Moscow: LKI, 2008. 440 p. (In Russ.)

Butanaev V. Ya. Khakass traditional food. In: [The Turko-Mongols: Excerpts from the History of Economy and Material Culture]. Novosibirsk: Nauka, 1993. Pp. 150-170. (In Russ.)

Dashibalov B.B. [Baikalian Siberia in the Middle Ages]. Ulan-Ude: Buryat State Univ., 1997. 67 p. (In Russ.)

Dashieva N. B. [Buryat Traditional Public Holidays: History and Typologies]. Ulan-Ude: EastSiberian State Inst. of Culture, 2012, 211 p. (In Russ.)

Dugarov B. S. Origins of the Oka Buryats revisited. In: [Ethnic, Historical and Cultural Ties of Mongolic Peoples]. Ulan-Ude: Bur. Affil. Inst. of Sib. Branch of USSR Acad. of Sc., 1983. Pp. 90-101. (In Russ.)

Fasmer M. [An Online Russian Etymological Dictionary]. An Internet resource: https://lexicography.online/etymology/ vasmer/\%D0\%BB/ (accessed: May 8, 2019). (In Russ.)

Galdanova G. R. [The Zakamensk Buryats]. Novosibirsk: Nauka, 1992. 170 p. (In Russ.)

Khangalov M. N. [Collected Works]. Ulan-Ude: Respublikanskaya Tipografiya, 2004. Vol. 1. 507 p. (In Russ.)

Klobukov B. The 1924-1925 State Fodder Balance of the Buryat Republic. Zhizn' Buryatii. 1925. No. 1-6. Pp.75-84. (In Russ.)

Kuryshov A. M. Western Buryats' farming culture. Journal of Economic History and History of Economics. 2014. Vol. 15. No. 3. Pp. 567-584. (In Russ.) 
Makchachkeeva G. V. Turkisms in the Alar dialect of the Buryat language. In: [Baikal Meetings $\mathrm{X}$ : Cultural Memory and Cultural Identity in the Context of Globalization]. Ulan-Ude: EastSiberian State Inst. of Culture, 2018. Pp. 374382. (In Russ.)

Mansheev D. M. Agriculture of the Alar Buryats in the $19^{\text {th }}$ century. Journal of Economic History and History of Economics. 2011. Vol. 12. No 1. Pp. 17-29. (In Russ.)

Pakhutov A. E. Revisiting a connection between the food system of Mongolic peoples and their economic-and-cultural type. In: [Material and Spiritual Culture of the Kalmyks]. Elista: Republ. Print. House, 1983. Pp. 27-36. (In Russ.)

Serebrennikov I. I. [The Buryats and Their Economic Lifestyles and Land Use Practices].
Verkhneudinsk, 1925. 226 p. (In Russ.)

Shchapov A. P. The Buryat ulus tribal community. Izvestiya Vostochno-Sibirskogo otdela RGO. 1875. Vol. 5. No. 3-9. (In Russ.)

Vorobyov N. I. [Material Culture of Kazan Tatars]. Kazan: House of Tatar Culture \& TNKP Academic Center, 1930. 464 p. (In Russ.)

Zimin Zh. A. [Alar: Past and Present. Book One: 'Alar, the Home Cradle]. Ulan-Ude: EastSiberian State Inst. of Culture, 2004. 203 p. (In Russ.)

Zimin Zh. A. Revisiting the exodus of Khongodor clans from Mongolia and their resettlement throughout Alar Region. In: [Ethnic, Historical and Cultural Ties of Mongolic Peoples]. UlanUde: Bur. Affil. Inst. of Sib. Branch of USSR Acad. of Sc., 1983. Pp. 102-113. (In Russ.) 